

Tersedia online di EDUSAINS

Website: http://journal.uinjkt.ac.id/index.php/edusains

EDUSAINS,11 (2), 2019, 303-309

Research Artikel

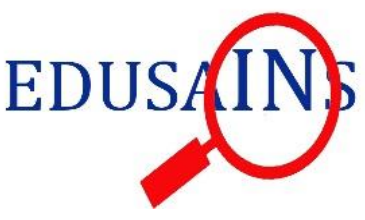

\title{
EFEKTIFITAS PELATIHAN LABORATORIUM VIRTUAL SEBAGAI MEDIA PEMBELAJARAN BAGI GURU KIMIA
}

\section{EFFECTIVITY OF VIRTUAL LABORATORY TRAINING AS A LEARNING MEDIA FOR CHEMISTRY TEACHERS}

Achmad Lutfi, Sukarmin

Universitas Negeri Surabaya, Indonesia achmadlutfi@unesa.ac.id

\begin{abstract}
The study aims to determine the level of training achievement using virtual laboratories for chemistry teachers on the ability of teachers to use virtual laboratories and the achievement of objectives in learning chemistry using virtual laboratories. The training was conducted for chemistry teachers who were members of the City and District High School Chemistry Teachers' Working Group (MGMP). During the study, the teachers were trained in how to install, operate virtual laboratories, and conduct experiments with virtual laboratories. At the end of the activity, an ability test was conducted using a virtual laboratory, giving questionnaires to participants and assigning participant assignments in the form of lesson plans (RPP) with the use of virtual laboratories as learning media. The data obtained showed that $90 \%$ of the participating teachers had been able to use virtual laboratory programs, including installing, operating, and conducting experiments with virtual laboratories. $82-100 \%$ of the participants found it useful to participate in the activities, and the compiled lesson plans showed that the participants were able to use the virtual laboratory as a medium for chemistry learning with a percentage of $85 \%-100 \%$, and students gave positive responses and good learning outcomes after participating in chemistry learning with use of virtual laboratories.
\end{abstract}

Keywords: Virtual laboratory; teacher; learning; chemistry; MGMP

\section{Abstrak}

Penelitian bertujuan mengetahui tingkat ketercapaian pelatihan menggunakan laboratorium virtual bagi guru kimia terhadap kemampuan guru menggunakan laboratorium virtual dan ketercapaian pembelajaran kimia dengan menggunakan laboratorium virtual. Pelatihan dilakukan terhadap guru kimia yang tergabung pada Musyawarah Guru Mata Pelajaran Kimia Sekolah Menengah Atas Kota dan Kabupaten Kediri. Selama penelitian dilatihkan cara menginstal, mengoperasikan laboratorium virtual dan melakukan percobaan dengan laboratorium virtual. Pada akhir kegiatan dilakukan tes kemampuan menggunakan laboratorium virtual, pemberian angket kepada peserta dan pemberian tugas peserta berupa pembuatan rencana pelaksanaan pembelajaran (RPP) dengan pemanfaatan laboratorium virtual sebagai media pembelajaran. Data yang diperoleh menunjukkan $90 \%$ guru peserta telah mampu menggunakan program laboratorium virtual, meliputi: menginstal, mengoperasikan, dan melakukan percobaan dengan laboratotium virtual. Sebesar 82-100\% peserta merasa bermanfaat mengikuti kegiatan dan RPP yang disusun memperlihatkan bahwa peserta sudah dapat memanfaatkan laboratorium virtual sebagai media pembelajaran kimia dengan prosentasi $85 \%-100 \%$, serta peserta didik memberikan tanggapan positif dan hasil belajar yang baik setelah mengikuti pembelajaran kimia dengan penggunaan laboratorium virtual.

Kata Kunci: laboratorium virtual; guru; pembelajaran; kimia; MGMP

Permalink/DOI: http://doi.org/10.15408/es.v11i2.11222 


\section{PENDAHULUAN}

Pembelajaran kimia selalu terkait dengan laboratorium, namun diperoleh data dari MGMP Kimia menunjukkan bahwa di SMA rata-rata sangat rendah penggunaan laboratorium dalam pembelajaran Kimia . Ada pada satu kelas melakukan praktikum di laboratorium berkisar 1-2 kali selama satu semester, ada yang selama satu tahun hanya 1-2 kali bahkan ada data yang menunjukkan bahwa melakukan praktikum hanya menjelang ujian kelulusan. Beberapa alasan yang diberikan tidak dilakukannya kegiatan praktikum antara lain: (a) tidak tersedia laboratorium, (b) bahan dan alat tidak tersedia, (c) tidak tersedia laboran, dan lain-lainnya.

Pelaksanaan kurikulum 2013 menuntut guru supaya berkreasi dalam proses belajar mengajar (PBM) agar pembelajaran berpusat pada peserta didik dengan memanfaatkan sarana dan prasarana yang ada, menerapkan media pembelajaran yang inovatif dengan harapan proses belajar mengajar menjadi bermakna bagi peserta didik. Salah satu bentuk kreatitas guru kimia dengan menjadikan laboratorium virtual sebagai media pembelajaran walaupun tidak dapat sepenuhnya menggantikan laboratorium. Namun dimaksudkan agar peserta didik lebih aktif selama pembelajaran dan dapat mencapai tujuan diperlukan dengan media pembelajaran yang tepat.

Ada sejumlah keuntungan yang dapat diperoleh dengan menggunakan laboratorium virtual dalam pembelajaran kimia, antara lain 1) Laboratorium virtual menjamin ketercapaian green chemistry; 2) Laboratorium virtual dapat mengakomodasi tiga level representasi kimia, yaitu level makroskopik, level mikroskopik dan level simbolik; 3) Laboratorium virtual dapat meningkatkan penguasaan konsep, keterampilan proses sains dan keterampilan berpikir kritis (Hikmah, 2017).

Perkembangan sains dan teknologi yang cepat serta tuntutan peserta didik terhadap penguasaan materi kimia perlu dilakukan upaya dalam pembelajarannya. Untuk memenuhi hal tersebut, guru harus kreatif dalam memilih media pembelajaran. Keberhasilan pembelajaran dipengaruhi oleh penggunaan media yang sesuai dengan tujuan tertentu. Media pembelajaran yang dipilih secara teliti dapat memenuhi tujuan pembelajaran berupa: memotivasi peserta didik, melibatkan peserta didik dalam pengalaman belajar yang bermakna, melaksanakan pembelajaran individual, menjelaskan dan menggambarkan materi pelajaran dan keterampilan kinerja, serta dapat memberi kesempatan untuk menganalisis kinerja individual dan perilaku.

Untuk menghadapi tantangan tersebut guru kimia di Kota dan Kabupaten Kediri telah memanfaatkan forum Musyawarah Guru Mata Pelajaran (MGMP) Kimia untuk saling bertukar pengalaman. MGMP Kimia Kota dan Kabupata Kediri telah melakukan komunikasi dengan ketua jurusan Kimia FMIPA Unesa untuk menyampaikan beberapa permasalahan yang dihadapi guru kimia dan program kerja MGMP Kimia SMA. Permasalahan yang disampaikan adalah guru kimia anggota MGMP memerlukan kemampuan menggunakan laboratorium virtual sebagai media pembelajaran kimia. Guru kimia SMA yang tergabung dalam MGMP kimia meminta diadakan pelatihan penggunaan media pembelajaran yang sesuai kebutuhan dengan alasan sebagai berikut: 1) materi kimia umumnya ditakuti peserta didik, sehingga perlu sesuatu yang menarik bagi peserta didik dan mudah untuk dipelajari, 2) sekolah umumnya telah memiliki peralatan multimedia seperti: Laptop dan LCD, tetapi belum digunakan secara maksimal, karena kekurangan program yang akan digunakan, dan 3) penggunaan laboratorium virtual diharapkan dapat mengurangi tidak keterlaksanaan percobaan pada pembelajaran kimia.

Media pembelajaran kimia, berupa laboratorium virtual seperti CHEM LAB (Chemical Laboratory) dapat mensimulasikan kegiatan laboratorium untuk tingkat SMA. Laboratorium virtual tersebut menampilkan kelengkapan dan tata letak didesain seperti laboratorium modern. Kondisi percobaan dibuat mirip seperti keadaan sesungguhnya, misalnya gelas kimia yang jatuh, air mengalir, ledakan, air mendidih, aliran gas, disertai suara pecah, perubahan warna dapat diamati dengan jelas. Laboratorium virtual lainnya adalah PhET (Physics Education Technology) adalah suatu 
simulasi interaktif di internet dengan memakai bahasa pemograman java dan flash, yang dikembangkan oleh tim dari Universitas Colorado Amerika Serikat. PhET telah mengembangkan serangkaian simulasi interaktif yang sangat menguntungkan dalam pengintegrasian teknologi komputer ke dalam pembelajaran.

Program tersebut cocok untuk mempermudah memahami proses eksperimen. Program ini kurang cocok untuk melatihkan keterampilan menggunakan alat-alat laboratorium. Sebagai salah satu upaya untuk mengatasi persoalan tersebut dilakukan pelatihan guru kimia yang tergabung dalam MGMP kimia Kota dan Kabupaten Kediri tentang penggunakan laboratorium virtual program CHEM LAB dan program PhET agar dapat diterapkan pada proses pembelajaran kimia di sekolah masing-masing.

Berdasarkan latar belakang, dapat diuraikan beberapa masalah penelitian: (a) Bagaimana kemampuan guru menginstal, mengoperasikan laboratorium virtual dan melakukan percobaan dengan laboratorium virtual setelah dilakukan pelatihan? (b) Bagaimana pelaksanaan pembelajaran kimia dengan menggunakan laboratorium virtual?.

\section{METODE}

Metode yang digunakan adalah metode tindakan atau eksperimen yang berupa pelatihan terhadap sasaran penelitian oleh dua instruktur. Peserta sasaran penelitian dilibatkan secara aktif dalam menginstal program, memahami isi program, menjalankan program dan mengaplikasikan di dalam kelas. Langkah yang akan ditempuh meliputi: a) Menginstal dan memberikan pemahaman isi dari program laboratorium virtual, b) Melatihkan penggunaan program laboratorium virtual, c) Penyusunan RPP untuk menerapkan program laboratorium virtual di kelas, dan menerapkan RPP yang telah disusun dalam pembelajaran di kelas.

Sasaran penelitian ini adalah 11 (sebelas) Guru Kimia Kota dan Kabupaten Kediri. Peserta yang dipilih berdasarkan: 1) kemampuan menjalankan komputer/laptop, 2) sekolah asal peserta memiliki sarana multimedia (komputer dan LCD), 3) bersedia menyebarluaskan cara menggunakan program Laboratorium Virtual kepada teman sejawatnya. Pemilihan sasaran dilakukan dengan melibatkan ketua MGMP Kimia Kota dan Kebupaten Kediri.

Agar pelaksanaan program penerapan Laboratorium Virtual ini dapat berjalan lancar dan mencapai hasil seperti yang diharapkan, maka evaluasi dan tindak lanjut. Evaluasi dilakukan mulai dari kegiatan perencanaan hingga pembuatan rencana pelaksanaan pembelajaran. Evaluasi dilakukan dengan: (1) melakukan tes kemampuan menggunanan laboratorium virtual, meliputi: menginstal program, mengoperasikan laboratorium virtual dan melakukan percobaan dengan laboratorium virtual, pengukuran dilakukan dengan observasi pada setiap peserta dengan kategori kurang (skor 1), cukup (skor 2), dan baik (skor 3); (2) melakukan angket pada peserta pelatihan dengan memilih 'ya' atau 'tidak'; dan (3) pemberian tugas menyusun RPP dengan penskoran 1 hingga 4 pada setiap butir yang dinilai. Indikator keberhasilan ketercapaian jika lebih dari $80 \%$ peserta pelatihan mempunyai kemampuan menggunakan laboratorium virtual, tanggapan peserta terhadap pelaksanaan pelatihan memperoleh persentasi lebih dari $80 \%$ menjawab 'ya', dan RPP yang disusun peserta memperoleh skor di atas $80 \%$, serta data pendukung lainnya berupa tanggapan peserta didik mencapai lebih $80 \%$ menyatakan 'ya', hasil belajar peserta didik pada penggunaan laboratorium virtual mencapai ketuntasan klasikal dan terjadi perbedaan yang signifikan antara skor awal dan skor akhir. Pengujian skor hasil belajar kimia awal dan akhir pembelajaran dilakukan uji t berpasangan dengan bantuan program SPPS versi 16.

\section{HASIL DAN PEMBAHASAN}

Kemampuan guru. Pengukuran kemampuan guru menginstal, mengoperasikan, dan melakukan percobaan dengan laboratorium virtual dilakukan setelah dilaksanakan pelatihan. Pengukuran dilakukan dengan observasi pada setiap peserta 
dengan kategori kurang (1), cukup (2), dan baik (3). Skor yang diperoleh disajikan dalam Tabel 1.

Tabel 1. Kemampuan Guru Peserta

\begin{tabular}{lllll}
\hline Aspek & \multicolumn{3}{l}{ Jumlah Guru Peserta } & Jml \\
\cline { 2 - 4 } Kemampuan & Skor & Skor & Skor & \\
$\begin{array}{l}\text { Menginstal } \\
\text { program }\end{array}$ & 0 & 0 & 11 & 11 \\
$\begin{array}{l}\text { Mengoperasikan } \\
\text { program }\end{array}$ & 0 & 1 & 10 & 11 \\
$\begin{array}{l}\text { Melakukan } \\
\text { percobaan }\end{array}$ & 0 & 1 & 10 & 11 \\
\hline
\end{tabular}

Berdasar hasil tes kemampuan peserta seluruhnya telah mampu menginstal program laboratorium virtual pada laptop yang dimiliki, kemampuan mengorasikan program hanya ada seorang yang mempunyai kemampuan cukup, dan juga pada kemampuan melakukan percobaan dengan menggunakan laboratorium virtual ada seorang peserta yang mendapat kategori cukup. Hasil wawancara menunjukkan bahwa peserta yang memperoleh skor cukup (skor 2) dikarenakan jarang bahkan tidak pernah menggunakan laptop, juga usia peserta tersebut sudah di atas 40 tahun, namun masih ada harapan untuk memperoleh skor 3 kategori baik bila berlatih lagi setelah kegiatan.

Hasil di atas menunjukkan bahwa 10 peserta atau $90 \%$ peserta sudah mempunyai kemampuan untuk menggunakan laboratorium virtual untuk media pembelajaran kimia di kelas, artinya kegiatan pelatihan telah memenuhi keefektifan berdasar skor kemampuan guru menggunakan laboratorium virtual.

Tanggapan Guru. Angket diberikan guru peserta dengan tujuan diperoleh tanggapan peserta atas penyelenggaraan pelatihan. Hasil angket tanggapan peserta setelah kegiatan pelatihan sebagai berikut.

Berdasar hasil yang ditunjukkan oleh Tabel 2, secara umum peserta menilai kegiatan pelatihan penggunaan laboratorium virtual dirasakan nyaman oleh peserta dan berguna peserta (guru). Guru menyatakan senang mengikuti pelatihan sebesar $100 \%$, dapat menerima materi yang disampaikan narasumber dengan baik sebesar $100 \%$, dan $91 \%$ merasa tidak terganggu. Data tersebut dapat diartikan bahwa kegiatan pelatihan dirasakan nyaman oleh peserta, sesuai dengan kebutuhan peserta, peserta merasa senang dapat menerima bahan yang disampaikan oleh narasumber dan kegiatan pelatihan tidak mengganggu aktivitas bapak/ibu guru.

Hasil yang sama juga diperoleh terhadap peserta didik yang telah mengikuti pembelajaran kimia dengan menggunakan laboratorium virtual, yaitu menyatakan merasa senang dengan mengikuti pembelajaran dengan menggunakan laboratorium virtual (Lutfi \& Hidayah, 2017 ). Kegiatan pelatihan yang pernah dilakukan di Banyuwangi juga menunjukkan bahwa guru kimia merasakan manfaat dari mengikuti pelatihan penggunaan laboratorium virtual sebagai media pembelajaran kimia (Hidayah, Sukarmin \& Lutfi, 2017).

Tabel 2. Hasil Respon Guru

\begin{tabular}{|c|c|c|c|}
\hline Tujuan & Pertanyaan & $\mathbf{Y a}$ & Tidak \\
\hline \multirow[t]{3}{*}{$\begin{array}{l}\text { Mengetahui } \\
\text { kenyamanan } \\
\text { pelatihan }\end{array}$} & $\begin{array}{lr}\text { 1. Apakah } & \text { Bapak/Ibu } \\
\text { merasa } & \text { senang } \\
\text { terhadap } & \text { kegiatan } \\
\text { pelatihan } & \text { yang } \\
\text { diselenggarakan } & \text { hari } \\
\text { ini? } & \end{array}$ & $\begin{array}{l}11 \\
(100 \%)\end{array}$ & $\begin{array}{l}0 \\
(0 \%)\end{array}$ \\
\hline & $\begin{array}{l}\text { 2. Apakah Bapak/Ibu } \\
\text { bisa menerima materi } \\
\text { yang disampaikan } \\
\text { oleh narasumber/ } \\
\text { dosen dengan baik? }\end{array}$ & $\begin{array}{l}11 \\
(100 \%)\end{array}$ & $\begin{array}{l}0 \\
(0 \%)\end{array}$ \\
\hline & $\begin{array}{l}\text { 3. } \begin{array}{ll}\text { Apakah } & \text { Bapak/Ibu } \\
\text { merasa } & \text { terganggu } \\
\text { dengan } & \text { mengikuti } \\
\text { kegiatan } & \text { pelatihan } \\
\text { seperti ini? }\end{array}\end{array}$ & $\begin{array}{l}1 \\
(9 \%)\end{array}$ & $\begin{array}{l}10 \\
(91 \%)\end{array}$ \\
\hline \multirow[t]{3}{*}{$\begin{array}{l}\text { Mengetahui } \\
\text { kegunaan } \\
\text { materi } \\
\text { pelatihan }\end{array}$} & $\begin{array}{l}\text { 4. Apakah Bapak/Ibu } \\
\text { kegiatan ini berguna } \\
\text { untuk } \\
\text { pembelajaran } \\
\text { di sekolah? }\end{array}$ & $\begin{array}{l}11 \\
(100 \%)\end{array}$ & $\begin{array}{l}0 \\
(0 \%)\end{array}$ \\
\hline & $\begin{array}{lr}\text { 5. Apakah } & \text { bahan } \\
\text { pelatihan } & \text { dapat } \\
\text { membantu } & \text { Bapak/Ibu } \\
\text { menyusun } & \text { persiapan } \\
\text { mengajar? }\end{array}$ & $\begin{array}{l}11 \\
(100 \%)\end{array}$ & $\begin{array}{l}0 \\
(0 \%)\end{array}$ \\
\hline & $\begin{array}{l}\text { 5. Apakah materi yang } \\
\text { diberikan termasuk } \\
\text { baru } \\
\text { Bapak/Ibu? }\end{array}$ & $\begin{array}{l}9 \\
(82 \%)\end{array}$ & $\begin{array}{l}2 \\
(18 \%)\end{array}$ \\
\hline \multicolumn{4}{|c|}{$\begin{array}{l}\text { Terkait kegunaan laboratorium virtual } \\
\text { sebagai bahan pelatihan, seluruh peserta (guru) } \\
100 \% \text { menyatakan berguna; terhadap pertanyaan } \\
\text { apakah akan dapat membantu menyusun persiapan } \\
\text { pembelajaran, seluruh peserta (guru) menjawab } \\
\text { 'ya' (100\%) artinya seluruh peserta (guru) }\end{array}$} \\
\hline
\end{tabular}


menyatakan akan dapat menyusun RPP dengan menggunakan media laboratorium virtual. Hasil yang menanyakan tentang keterbaharuan materi pelatihan, diperoleh sebanyak 2 peserta (18\%) menyatakan pernah menerima hanya saja tidak selengkap pada pelatihan kali ini dan $82 \%$ peserta menjawab termasuk baru. Namun, berdasar wawancara, diperoleh informasi seluruh peserta belum pernah menerapkan di kelas.

Hasil pada Tabel 2 dapat diartikan pelatihan dengan materi laboratorium dirasakan berguna untuk pembelajaran kimia. Hal tersebut sesuai dengan penelitian yang menyatakan laboratorium virtual baik digunakan sebagai media pembelajaran kimia dan dapat membantu guru menciptakan pembelajaran berpusat pada peserta didik (Lutfi, 2017).

Selain menjawab pertanyaan pada angket, peserta (guru) juga diberi kesempatan untuk menyampaikan pendapat tentang pelatihan yang sudah dilaksanakan. Para peserta (guru) menyatakan bahwa pelatihan menyenangkan; bermanfaat untuk mengajar kimia di kelas, dan merasa dapat digunakan sebagai pengganti praktikum yang tidak dapat dilakukan di sekolah. Pendapat yang diutarakan oleh peserta (guru) tersebut mengkonfirmasi hasil yang ditunjukkan pada Tabel 2. Dengan demikian, tanggapan dari peserta (guru) yang merupakan anggota MGMP Kimia mengenai pelatihan penggunaan laboratorium virtual sebagai media pembelajaran kimia tergolong baik dan mempunyai keinginan menyebarluaskan kepada sesama guru kimia di Kota dan Kabupaten Kediri.

Penilaian RPP. Penilaian terhadap RPP yang disusun peserta setelah mengikuti pelatihan diperoleh hasil yang disajikan pada Tabel 3.

Tabel 3. Hasil Penilaian RPP

\begin{tabular}{|c|c|c|}
\hline No & Aspek penilaian & Penilaian \\
\hline 1 & $\begin{array}{l}\text { RPP menggunakan media laboratorium } \\
\text { virtual }\end{array}$ & $\begin{array}{l}4,0 \\
(100 \%)\end{array}$ \\
\hline 2 & $\begin{array}{l}\text { Laboratorium virtual yang digunakan } \\
\text { sesuai dengan tujuan pembelajaran } \\
\text { Kimia pada RPP }\end{array}$ & $\begin{array}{l}3,8 \\
(95 \%)\end{array}$ \\
\hline 3 & 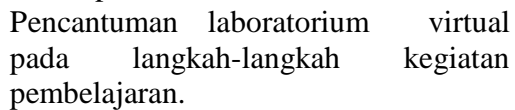 & $\begin{array}{l}3,9 \\
(96 \%)\end{array}$ \\
\hline
\end{tabular}

\begin{tabular}{lll}
\hline No & Aspek penilaian & Penilaian \\
\hline 4 & $\begin{array}{l}\text { Dalam RPP direncanakan diperoleh } \\
\text { data dari laboratorium virtual yang } \\
\text { digunakan }\end{array}$ & $(85 \%)$ \\
\hline
\end{tabular}

Berdasar data pada Tabel 3, penilaian terhadap RPP peserta (guru) mencapai kriteria yang ditentukan yaitu $80 \%$ dan bahkan ada yang telah mencapai $100 \%$, yaitu pada keberadaan laboratorium virtual dalam RPP sebagai media pembelajaran. Artinya RPP yang disusun peserta (guru) telah mencantumkan laboratorium virtual sebagai media pembelajaran dan media yang dipilih sesuai dengan tujuan pembelajaran yang direncanakan. Aspek yang terendah diperoleh pada rencana penggunaan media untuk mengumpulkan data yaitu $85,5 \%$, namun telah memenuhi kriteria dan mendapat penilaian $96 \%$ pada aspek RPP menyertakan langkah-langkah penggunaan laboratorium virtual. Artinya RPP yang disusun telah dirancang menggunakan langkah-langkah tertentu dalam menggunakan laboratorium virtual sehingga diperoleh data percobaan, hasil ini sesuai dengan pendapat Smaldino, dkk. (2019) bahwa pengunaan media yang sesuai akan dapat mencapai tujuan pembelajaran. Hasil ini mempunyai harapan besar, guru akan dapat melaksanakan pembelajaran dengan laboratorium virtual sesuai RPP yang disusun.

Hasil Penerapan RPP. Salah satu RPP yang disusun diterapkan dalam pembelajaran kimia pokok bahasan Teori-teori Asam Basa di sekolah pada salah satu kelas, sebelum pembelajaran dilakukan tes awal dan setelah pembelajaran peserta didik diberikan angket dan tes hasil belajar. Hasil angket peserta didik disajikan pada Tabel 4.

Tabel 4. Hasil Angket Peserta didik

\begin{tabular}{|c|c|c|c|}
\hline \multirow[t]{2}{*}{ No } & \multirow[t]{2}{*}{ Pernyataan } & \multicolumn{2}{|c|}{ Hasil Angket } \\
\hline & & Ya & Tidak \\
\hline 1 & $\begin{array}{l}\text { Kegiatan pembelajaran } \\
\text { dengan laboratorium virtual } \\
\text { yang telah saya ikuti, lebih } \\
\text { mudah memahami materi } \\
\text { yang diajarkan. }\end{array}$ & $\begin{array}{l}29 \\
(93,5 \%)\end{array}$ & $\begin{array}{l}2 \\
(6,5 \%)\end{array}$ \\
\hline 2 & $\begin{array}{l}\text { Adanya kegiatan } \\
\text { pembelajaran yang telah saya } \\
\text { ikuti, saya menjadi lebih aktif } \\
\text { mengikuti pembelajaran. }\end{array}$ & $\begin{array}{l}31 \\
(100 \%)\end{array}$ & $\begin{array}{l}0 \\
(0 \%)\end{array}$ \\
\hline 3 & $\begin{array}{l}\text { Kegiatan pembelajaran tadi } \\
\text { memudahkan saya dalam } \\
\text { memecahkan permasalahan }\end{array}$ & $\begin{array}{l}29 \\
(93,5 \%)\end{array}$ & $\begin{array}{l}2 \\
(6,5 \%)\end{array}$ \\
\hline
\end{tabular}




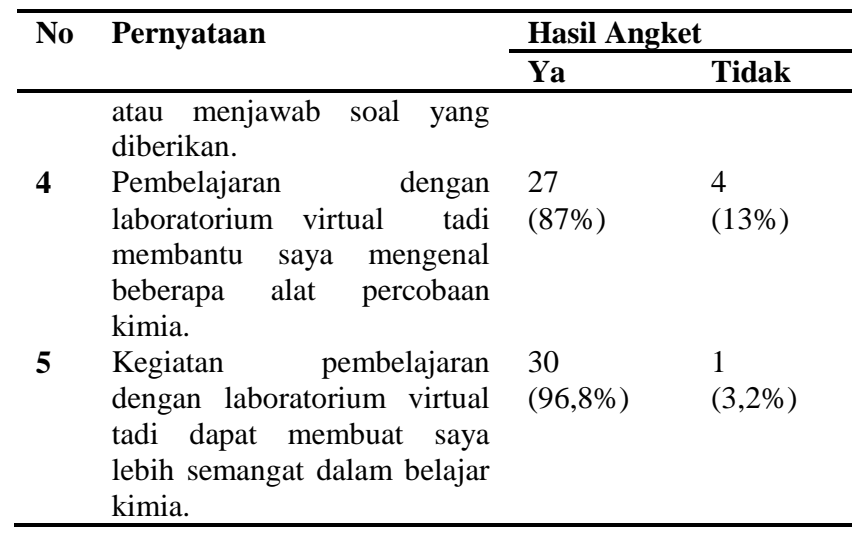

Hasil angket pada Tabel 4 memperlihatkan peserta didik memberikan tanggapan yang positif terhadap penggunaan laboratorium virtual sebagai media pembelajaran Teori Asam Basa. Peserta didik merasakan adanya laboratorium virtual selama pembelajaaran menciptakan pembelajaran lebih aktif, hal ini didasarkan hasil angket bahwa seluruh peserta didik (100\%) menyetujui pernyataan tersebut. Tanggapan yang paling rendah (87\%) pada pernyataan pembelajaran bahwa dengan laboratorium virtual tadi membantu saya mengenal beberapa alat percobaan kimia, hal ini dapat terjadi karena selama pembelajaran hanya menggunakan satu program laboratorium virtual dan baru kali pertama di kelas tersebut menggunakan laboratorium virtual. Peserta didik menyatakan penggunaan laboratorium virtual membuat lebih semangat dalam belajar kimia. Terhadap penyataan yang lain, masih ada peserta didik yang tidak setuju (menjawab 'tidak'), namun sudah sebagian besar peserta didik menyatakan setuju (ya). Hal ini dimungkinkan karena peserta didik belum dapat dengan baik menggunakan komputer/program dan latihan atau tantangan yang diberikan oleh guru masih pada tingkat awal/dasar.

Hasil tes awal dan akhir pembelajaran dengan menggunakan laboratorium virtual disajikan pada Tabel 5 .

Tabel 5. Hasil Belajar Peserta didik

\begin{tabular}{llll}
\hline Kondisi & Jumlah & \multicolumn{2}{l}{ Ketuntasan } \\
\cline { 3 - 4 } & Peserta didik & Jumlah & Persentase \\
Tes awal & 31 & 2 & $6,45 \%$ \\
Tes Akhir & 31 & 29 & $93,55 \%$ \\
\hline
\end{tabular}

Data Tabel 5 memperlihatkan terjadi kenaikan jumlah ketuntasan dari tes awal dan tes akhir. Untuk mengetahui perbedaan rata-rata skor tes awal dan tes akhir dilakukan uji t berpasangan dan terlebih dulu diuji normalitas kedua kelompok dengan bantuan program SPSS.

Tabel 6. Uji t Pretest dan Posttest Peserta Didik

\begin{tabular}{|c|c|c|c|}
\hline \multicolumn{4}{|c|}{ One-Sample Kolmogorov-Smirnov Test } \\
\hline & & skor pre & $\begin{array}{l}\text { skor } \\
\text { post }\end{array}$ \\
\hline \multirow{3}{*}{$\begin{array}{l}\text { N } \\
\text { Normal Parameters }\end{array}$} & & 31 & 31 \\
\hline & Mean & 29.19 & 83.5484 \\
\hline & $\begin{array}{l}\text { Std. } \\
\text { Deviation }\end{array}$ & 18.26 & 7.98 \\
\hline \multirow{2}{*}{$\begin{array}{l}\text { Most } \\
\text { Differences }\end{array}$} & Absolute & .192 & .220 \\
\hline & $\begin{array}{l}\text { Positive } \\
\text { Negative }\end{array}$ & $\begin{array}{l}.192 \\
-.154\end{array}$ & $\begin{array}{l}.220 \\
-.199\end{array}$ \\
\hline \multirow{2}{*}{\multicolumn{2}{|c|}{$\begin{array}{l}\text { Kolmogorov-Smirnov } Z \\
\text { Asymp. Sig. (2-tailed) } \\
\text { a. Test distribution is Normal. }\end{array}$}} & 1.07 & 1.23 \\
\hline & & .203 & .099 \\
\hline
\end{tabular}

Berdasar Tabel 6 menunjukkan nilai signifikasi diperoleh 0,203 dan 0,099 harga tersebut lebih besar dari 0,05 , berarti kedua kelompok berdistribusi normal sehingga dapat diuji dengan uji t sampel berpasangan (Nurhasanah, 2019). Hasil uji t berpasangan ditunjukkan pada Tabel 7 .

Tabel 7. Uji t Perpasangan

\begin{tabular}{llll}
\hline Skor & Rata-rata & df & Harga t \\
\hline Tes Awal & 29.1935 & 30 & 16.26 \\
Tes Akhir & 83.5484 & & \\
\hline
\end{tabular}

Telah diperoleh harga $\mathrm{t}$ sebesar 16,26, harga $\mathrm{t}$ hitung yang diperoleh berada pada daerah penolakan hipotesis nol dan penerimaan hipotesis alternatif, yaitu ada perbedaan yang signifikan (5\%) antara rata-rata skor tes awal dan skor tes akhir. Artinya pembelajaran Teori Asam Basa dengan menggunakan laboratorium virtual, skor hasil belajar yang diperoleh peserta didik memperlihatkan terjadi peningkatan yang signifikan dibanding skor sebelum pembelajaran serta dapat mencapai ketuntasan klasikal. Hasil ini sesuai dengan hasil penelitian Alatas dan Fachrunisa (2018) yang menyatakan laboratorium virtual mampu memudahkan peserta didik untuk bereksplorasi sehingga mencapai hasil belajar yang optimal. Juga sesuai hasil penelitian yang menyatakan penggunaan laboratorium virtual dapat meningkatkan hasil belajar peserta didik (Astuti \& Handayani, 2018). 


\section{PENUTUP}

Pelatihan penggunaan laboratorium virtual yang dilakukan kepada guru anggota MGMP Kimia Kota dan Kabupaten Kediri telah diperoleh bahwa mencapai keefektifan yang tinggi. Hal itu didasarkan pada skor kemampuan guru menggunakan laboratorium virtual mencapai $90 \%$, tanggapan yang positif guru peserta $82 \%-100 \%$ dan guru telah mampu menyusun RPP dengan menyertakan laboratorium virtual sebagai media pembelajaran dengan memperoleh skor $85 \%-100 \%$ di atas kriteria yang ditentukan. Pada penerapan RPP yang disusun guru telah memperoleh tanggapan baik oleh peserta didik, yaitu lebih dari $80 \%$ dan skor tes akhir belajar peserta didik telah mencapai ketuntasan klasikal yaitu telah mencapai lebih dari $80 \%$ tuntas dan terdapat perbedaan yang signifikan antara skor rata-rata tes awal dibanding skor rata-rata tes akhir.

Adapun saran yang dapat diberikan dari penelitian ini adalah: hasil kegiatan pelatihan yang dilakukan oleh tim Jurusan Kimia FMIPA Unesa perlu disebarluaskan oleh peserta (guru) kepada anggota MGMP Kimia Kota dan Kabupaten Kediri yang belum sempat mengikuti kegiatan pelatihan dan hendaknya laboratorium virtual dijadikan suatu arternatif media pembelajaran kimia di kelas karena telah menunjukkan tanggapan yang positif oleh peserta didik dan hasil belajar yang baik, namun masih diperlukan kegiatan laboratorium kimia yang sebenarnya terutama untuk mencapai tujuan pada ranah psikomotor.

\section{DAFTAR PUSTAKA}

Alatas, F. dan Fachrunisa, Z. 2018. An Effective Of Pogil With Virtual Laboratory In Improving Science Process Skills And Attitudes: Simple Harmonic Motion Concept. Jurnal Edusains. 10 (2), 2018, 327 - 334. Website: http://journal.uinjkt.ac.id/index.php/

Astuti, I.A.D. dan Handayani, S. 2018. Penggunaan Virtual Laboratory berbasis PhET Simulation Untuk Menentukan Konstanta Wien. Jurnal Penelitian Pembelajaran Fisika Vol. 9 No. 2 September 2018, p66-72.
Hidayah, R, Sukarmin, Lutfi, A. 2017. Pelatihan Penggunaan Laboratorium Virtual Sebagai Media Pembelajaran Kimia Bagi Guru Di MGMP Kimia Kabupaten Banyuwangi. Jurnal ABDI. Vol.2 No.2: hal. 87 - 90.

Hikmah, N., Saridewi, N., Agung, S. 2017. Penerapan Laboratorium Virtual Untuk Meningkatkan Pemahaman Konsep Siswa. Jurnal Kimia dan Pendidikan (EduChemia). Vol.2 (2).

Lutfi, A. 2017. Pengembangan Media Laboratorium Virtual Bersarana Komputer Untuk Melatih Berpikir Kritis Pada Pembelajaran Asam, Basa, dan Garam. Jurnal Penelitian Pendidikan Matematika dan Sains. JPPMS, Vol. 1, No. 1, 2017 http://journal.unesa.ac.id/index.php/jppms/

Lutfi, A. and Hidayah, R. 2017. Training Science Process Skills Using Virtual Laboratory On Learning Acid, Base, And Salt. Journal of Chemistry Education Research ISSN: $2549-$ 1644. Vol. 1, No. 1, December 2017. https://journal.unesa.ac.id/index.php/jcer/arti cle/view/2180/1414.

Mendikbud RI. 2014. Permendikbud No. 59, 2014 Tentang Kurikulum 2013 Sekolah Menengah Atas/Madrasah Aliyah, Lampiran. Jakarta: Mendikbud.

Nurhasanah, S. 2019. Statistika Pendidikan, TeoriAplikasi dan Kasus. Malang: Salemba Humanika.

Smaldino, S. E., Lowther, D. L., and Clif, M. 2019. Instructional Technology and Media for Learning 12th Edition. United States of America: Pearson Education, Inc. All Rights Reserved. 